\title{
Identification of Sortase A (SrtA) Substrates in Streptococcus uberis; Evidence for an Additional Hexapeptide (LPXXXD) Sorting Motif.
}

\section{Sharon A Egan', Dominic Kurian², Philip N Ward³, Lawrence Hunt ${ }^{2}$ \& James A Leigh $^{1}$}

${ }^{1}$ The School of Veterinary Medicine and Science, The University of Nottingham, Sutton Bonington Campus, Sutton Bonington, Leicestershire, LE12 5RD,UK

${ }^{2}$ Institute for Animal Health, Compton, Berkshire, RG20 7NN, UK

${ }^{3}$ Nuffield Department of Clinical Laboratory Sciences, Oxford University, John Radcliffe Hospital, Headington, OX3 9DU, UK.

\begin{abstract}
Sortase (a transamidase) has been shown to be responsible for the covalent attachment of proteins to the bacterial cell wall. Anchoring is effected on secreted proteins containing a specific cell wall motif towards their C-terminus; that for sortase $A(S r t A)$ in Gram positive bacteria often incorporates the sequence LPXTG. Such surface proteins are often characterised as virulence determinants and play important roles during the establishment and persistence of infection. Intra-mammary infection with Streptococcus uberis is a common cause of bovine mastitis, which impacts on animal health and welfare and the economics of milk production. Comparison of stringently produced cell wall fractions from $S$. uberis and an isogenic mutant strain lacking SrtA permitted identification of 9 proteins likely to be covalently anchored at the cell surface. Analysis of these sequences implied the presence of two anchoring motifs for $S$. uberis, the classical LPXTG motif and an additional LPXXXD motif.
\end{abstract}


Key Words: sortase A, LPXTG, cell wall proteins, mastitis, Streptococcus uberis Introduction

Virulence determinants associated with the bacterial cell surface play an important role in the persistence and pathogenesis of bacterial infections through such processes as adherence to, and invasion of, host cells and subversion of the host response ${ }^{1}$. The proteins involved are often candidates for inclusion in vaccines or targets for new therapeutic agents ${ }^{2,3}$.

The surface of Gram-positive bacteria is decorated with many different macromolecules, including carbohydrates, teichoic acids, polysaccharides and proteins. In many species a subset of surface proteins have been reported to be covalently linked to the peptidoglycan matrix of the cell wall ${ }^{1,4,5}$. In almost all studies to date, in Gram positive bacteria, several Archaea and Gram negative Proteobacteria, the mechanism of the covalent attachment of proteins relies on the transamidase, sortase ${ }^{6}$. Sortase was first described in Staphylococcus aureus ${ }^{7}$ and presently, five different classes of sortase enzyme have been identified in Gram positive bacteria ${ }^{8,9}$. Each class has been reported to anchor a specific and discrete subset of proteins by recognition of a distinct pentapeptide motif within a suitable context within the substrate protein.

The majority of covalently attached proteins are anchored by a single transpeptidase, sortase A (SrtA). Bacteria deficient in SrtA display an altered array of surface proteins and often altered virulence characteristics due to the lack of properties specifically associated with the sortase substrate proteins ${ }^{5}$. Anchoring of proteins by SrtA is dependent on the substrate containing a signal peptide and a cell wall sorting motif. In many studies this has been shown to consist of a penta-peptide, typically, but not 
exclusively, documented as LPXTG. This is typically followed by a C-terminal hydrophobic region and a short tail of charged amino acids at the C-terminus ${ }^{10}$. In most cases, the sorting motif is located towards the C-terminus of the anchored protein, however in one case, an IgA protease from Streptococcus pneumoniae, a functional sorting motif was demonstrated towards the $\mathrm{N}$-terminus of the protein ${ }^{11}$.

Characterization of the activity and specificity of SrtA has been based primarily on studies conducted on Staphylococcus aureus. In general, covalent attachment to the peptidoglycan follows secretion of the substrate protein via the Sec pathway and the concomitant cleavage of the $\mathrm{N}$-terminal signal sequence (reviewed with particular reference to streptococcal and mycobacterial species in Rigel and Braunstein ${ }^{12}$ ). The secreted protein which is retained at the bacterial cell surface due to the hydrophobic domain and the positively charged C-terminus, is cleaved by SrtA between the threonine and glycine of the LPXTG motif ${ }^{13,14}$. SrtA subsequently effects the formation of a new amide bond between the resulting C-terminal threonine and the amine group of the penta-glycine peptides that form cross-bridges within the peptidoglycan ${ }^{15}$. In streptococci the process is considered similar except that anchoring occurs between the substrate protein and the respective cross bridging peptide, penta-glycine being exclusive to Staphylococci. A recombinant version of SrtA from S. pyogenes was shown in vitro to catalyse the transpeptidation of LPXTG containing peptides to a di-alanine cell wall precursor mimic ${ }^{16}$.

Combining data from in silico genomic searches using algorithms such as PSORT with that from experimental detection of proteins in bacterial extracts ${ }^{17,}{ }^{18}$, has enabled identification of putative SrtA substrates. Alternatively, in silico analysis of genomic sequences utilising hidden Markov models ${ }^{19}$ or the generation of alternative pattern 
searching algorithms ${ }^{4}$ have provided definitive lists of putative SrtA substrates that can be validated experimentally. However, sortase-anchored proteins that do not contain typical cell wall sorting motifs may not be identified using such approaches.

Experimental identification of SrtA anchored proteins has proven difficult due to the presence of contaminating proteins. This has necessitated the production of extracts from highly purified cell wall fractions for analysis. A number of studies have used 2-DE and/or LCMS to identify sortase anchored proteins from bacterial cell wall fractions of staphylococcal and streptococcal species ${ }^{20-26}$. These studies focused on analysis of fractions generated using cell wall hydrolysing enzymes such as mutanolysin or lysostaphin under osmotically protected conditions in an attempt to release proteins specifically from bacterial peptidoglycan. However, in almost all cases, the number of covalently anchored proteins identified was much lower than that predicted by bioinformatic analysis of the genome sequence. This may reflect the low abundance or lack of expression of these proteins in vitro, or may be due to inadequate separation and resolution of the target proteins; particularly during the isoelectric focusing of highly hydrophobic, highly basic, highly acidic or very large or small proteins attached to fragments of peptidoglycan ${ }^{27,28}$. Direct tryptic-digestion of purified cell wall fractions 29,30 or shaving of intact bacterial cells with trypsin ${ }^{18,31}$ and detection of the resulting peptides by LCMS/MS has been applied to identify increased numbers of surface associated proteins.

Streptococcus uberis is one of the most common pathogens associated with bovine mastitis ${ }^{32,}{ }^{33}$ and impacts on animal health and welfare and the economics of milk production. The published genome of $S$. uberis (strain 0140J) contains a single coding sequence (CDS) with homology to SrtA ${ }^{34}$ and seven CDSs containing an LPXTG motif 
within a suitable context ${ }^{34}$. Bioinformatic analysis of the genome also revealed a further two CDSs with a possible LPXAG sorting motif and a number of other CDSs that showed homology to proteins shown to be anchored in other Gram-positive bacteria but which lacked a recognised motif sequence ${ }^{34}$.

In this communication, we compared the proteomic analysis of tryptic peptides shaved from isolated cell walls of $S$. uberis and an isogenic, sortase-deficient mutant and discuss the output in the context of the identification/validation of SrtA anchored proteins, the sorting motif and the specificity of SrtA.

\section{Methods}

\section{Bacterial strains and reagents:}

S. uberis strain 0140J (strain ATCC BAA-854 / 0140J), originally isolated from a clinical case of bovine mastitis in the UK, was used throughout this study. The SrtA mutant was isolated following PCR screening of a S. uberis 0140J pGh9::ISS1 mutant bank ${ }^{35}$ following a similar protocol to that described previously ${ }^{36}$. The bacterium was routinely grown in Todd Hewitt (THB) or Brain Heart Infusion (BHI) broth (Oxoid Ltd, Cambridge UK) at $37^{\circ} \mathrm{C}$.

\section{Isolation of cell wall proteins:}

Cell wall protein isolation was adapted from methods previously described ${ }^{30,37}$. Briefly, bacterial cultures were grown in either $\mathrm{THB}$ or $\mathrm{BHI}$ to either exponential or stationary phases of growth. Exponential cultures were grown in 1.5 litres of broth to an optical density of 0.6 at $\mathrm{OD}_{550 \mathrm{~nm}}$ whilst stationary phase cultures were grown in 1 litre of broth overnight. Bacteria were harvested by centrifugation $\left(16,000 \times g, 10 \mathrm{~min}, 4^{\circ} \mathrm{C}\right)$ and 
washed consecutively with PBS, $0.1 \%$ (v/v) Nonidet P40 (NP40) (Sigma-Aldrich, St Louis, MO, USA) in PBS, and PBS. Bacteria were finally resuspended in PBS containing Complete protease inhibitors (Roche Diagnostics $\mathrm{GmbH}$, Mannheim, Germany) and disrupted by bead beating in screw-capped microfuge tubes containing $0.1 \mathrm{~mm}$ zirconia/silica beads in $5 \times 1$ min intervals at maximum speed, with interspersed cooling periods on ice. Unbroken cells and beads were removed by two rounds of centrifugation $\left(8,000 \times g, 10 \mathrm{~min}, 4^{\circ} \mathrm{C}\right)$. The supernatants were then subjected to high speed centrifugation $(125,000 \times g, 30 \mathrm{~min})$ and the resulting pellets resuspended in $4 \%$ SDS/PBS, heated at $80^{\circ} \mathrm{C}$ for 4 hours, then centrifuged $(200,000 \times g, 30 \mathrm{~min})$. The resulting cell wall fragments were washed 4 times with MilliQ water at $30^{\circ} \mathrm{C}$, harvested by centrifugation (as above). The washed cell wall fragments were resuspended in 50 $\mathrm{mM}$ ammonium bicarbonate containing $1 \mu \mathrm{g}$ of proteomics grade trypsin (Sigma) in a final volume of $200 \mu \mathrm{l}$ and incubated with shaking overnight at $37^{\circ} \mathrm{C}$. The samples were clarified by centrifugation $(16,000 \times g, 10 \mathrm{~min})$ and the tryptic digestion stopped by the addition of formic acid (Sigma) to a final concentration of $0.1 \%$; w/v.

\section{Preparation of S. uberis concentrated culture supernatant}

Complete protease inhibitors were added to cultures $(400 \mathrm{ml})$ of $S$. uberis $0140 \mathrm{~J}$ and its isogenic SrtA mutant grown overnight in THB. Bacteria were removed from culture supernatant by centrifugation $(16,000 \times g, 10 \mathrm{~min})$. The bacterial growth media was filter sterilised through a $0.22 \mu \mathrm{M}$ filter (Millipore, Bedford, MA, USA) and concentrated approximately 100-fold using Amicon centrifugal filter devices (Millipore) with 10kDa molecular weight cut off. To precipitate proteins, 4 volumes of methanol and chloroform (3:1) was added to 1 volume of concentrated bacterial growth media. The preparation was vortexed and 2 volumes of MilliQ water were added prior to centrifugation $(16,000 \times$ g, 2 min). The upper phase was carefully removed and discarded. Proteins were 
precipitated with 3 volumes of methanol, and collected by centrifugation $(16,000 \times g, 2$ min). The supernatant was discarded and the remaining pellet air-dried before resuspension in SDS-PAGE-loading buffer.

\section{Production and purification of recombinant sub0826, sub1154 and sub1370}

The predicted mature coding sequence of sub0826, sub1154 and sub1370 were amplified from genomic DNA by PCR using primer pairs

p451 (5'-GATGAAAAAGTGATTAATGGTTCAGA-3') and

p452 (5'-TAGTTCCGATGTCGACCTTTTGTT-3'),

p409 (5'-GAGCAATTGCAAAATGAAAAGC-3') and

p410 (5'-ATGTCAAAAGCCCGGTACCTTTACAG-3')

p480 (5'- GAAGAAGTGGTAACTGCTACAAAC-3') and

p481 (5'- TACTAACTTCTTGTCATCTTGGTACCTTTT), respectively. Each set of primers was designed to incorporate either a Kpnl restriction site (sub1154 and sub1370) or a Sall restriction site (sub0826) to enable efficient directional cloning.

Amplicons were generated for each construct (4.4 kb for Sub0826, 3.4 kb for Sub1154 and $3.1 \mathrm{~kb}$ for Sub1370) using Phusion ${ }^{\mathrm{TM}}$ high fidelity polymerase (New England Biolabs, Ipswich, MA, USA), purified using a MinElute PCR Purification Kit (Qiagen $\mathrm{GmbH}$, Hilden, Germany) and treated with Kpnl or Sall (New England Biolabs) to facilitate directional cloning. Plasmid pQE1 (Qiagen) was digested with Kpnl or Sall and treated with Antarctic phosphatase (all from New England Biolabs), to prevent self ligation. The amplicon and plasmid were ligated using T4 DNA Ligase (New England Biolabs) at $14^{\circ} \mathrm{C}$ according to the manufacturers' instructions. Twenty microlitres of the ligation mixture was desalted ${ }^{38}$ and approximately $10 \mathrm{ng}$ of the desalted ligation mixture 
was transformed into Escherichia coli M15 pREP4 (Qiagen). Recombinant clones were selected on LB Kan ${ }^{25 \mu g / m l}$ Amp ${ }^{50 \mu g / m l}$ agar plates.

Overnight cultures containing each recombinant (6 x His-tagged) protein were subcultured by dilution (1/30) into LB broth containing $50 \mu \mathrm{g} / \mathrm{ml}$ of ampicillin and $25 \mu \mathrm{g} / \mathrm{ml}$ of kanamycin and grown at $20^{\circ} \mathrm{C}$ (sub1154 and sub0826) without shaking or $37^{\circ} \mathrm{C}$ (sub1370) with agitation (200rpm) for $2 \mathrm{~h}$. Protein expression was induced by addition of IPTG to a final concentration of $0.2 \mathrm{mM}$. Cultures were incubated for a further $2-4 \mathrm{hrs}$ and bacterial cells harvested by centrifugation $(8,000 \times g ; 20 \mathrm{~min})$. Bacteria were lysed by the addition of CelLytic (Sigma) in the presence of protease inhibitors (CompleteEDTA free; Roche) and recombinant proteins purified in the presence of the same inhibitors using HisSelect high flow cartridges (Sigma) according to the manufacturers' instructions.

\section{Production of Sub0826, Sub1154 and Sub1370 antiserum in rabbits and immuno- blotting}

Five aliquots of approximately $50 \mu \mathrm{g}$ freeze dried purified recombinant protein were supplied to Davids Biotechnologie (Regensburg, Germany) for serum production in rabbits. Anti-serum $(50 \mathrm{ml})$ was supplied filter sterilised and containing $0.02 \%$ sodium azide as a preservative.

Detergent and media bacterial extracts were separated by sodium-dodecyl sulphate polyacrylamide (SDS-PAGE) on $10 \%$ gels and either transferred onto nitrocellulose membranes (Amersham Biosciences UK, Little Chalfont, UK) for immuno-detection or incubated in InstantBlue (Expedeon Protein solutions, Cambridge, UK) for detection of proteins. Transfer was performed at $170 \mathrm{~mA}$ for $1 \mathrm{hr}$ in a (Biorad) Transblot apparatus in 
transfer buffer consisting of $25 \mathrm{mM}$ Tris-base, $192 \mathrm{mM}$ glycine and $20 \%(\mathrm{v} / \mathrm{v})$ methanol, $\mathrm{pH}$ 8.1-8.4. Membranes were incubated in a blocking solution of $1 \%$ skimmed milk powder in PBS at $4^{\circ} \mathrm{C}$ overnight, washed three times for 5 min in PBS containing $0.1 \%$ Tween 20 (PBST) and then incubated for $1 \mathrm{hr}$ in rabbit antisera diluted (1/5,000 antisub0826; 1/10,000 anti-sub1154 or 1/15,000 anti-sub1370) in blocking solution. Membranes were washed three times for $5 \mathrm{~min}$ in PBST then incubated with goat antirabbit immunoglobulin G conjugated to HRP (Southern Biotech, Birmingham, AL, USA) diluted 1/1000 in blocking buffer, for 1 hour. Membranes were washed (as above) and HRP conjugate detected using a solution of 4 -chloronaphthol $(0.5 \mathrm{mg} / \mathrm{ml})$ in PBS containing $16.7 \%$ methanol and $0.00015 \%(v / v)$ of $\mathrm{H}_{2} \mathrm{O}_{2}$ following incubation under dark conditions for 1 hour. Membranes were subsequently rinsed in PBS and allowed to dry.

\section{Peptide analysis by LC-MS}

LC MS/MS analysis was performed on a nanoAcquity UPLC system coupled to Q-Tof Premier Mass spectrometer (Waters Corporation). Tryptic peptides were desalted and concentrated on a C18 TRAP $(180 \mu \mathrm{m} \times 20 \mathrm{~mm}, 5 \mu \mathrm{m}$ Symmetry, Waters), for $3 \mathrm{~min}$ at $10 \mu \mathrm{l} / \mathrm{min}$ with $0.1 \%(\mathrm{v} / \mathrm{v})$ Formic acid, and resolved on a $1.7 \mu \mathrm{m} \mathrm{BEH} 130 \mathrm{C} 18$ column $(100 \mu \mathrm{m} \times 100 \mathrm{~mm}$, Waters) attached to Waters UPLC Acquity HPLC. Peptides were eluted at $400 \mathrm{nl} / \mathrm{min}$ with a linear gradient of $0-50 \%(\mathrm{v} / \mathrm{v})$ acetonitrile/ $0.1 \%(\mathrm{v} / \mathrm{v})$ formic acid over $30 \mathrm{~min}$, followed by $85 \%(\mathrm{v} / \mathrm{v})$ acetonitrile/ $0.1 \%(\mathrm{v} / \mathrm{v})$ formic acid for $7 \mathrm{~min}$. Eluted peptides were analysed on Q-Tof Mass Spectrometer in data directed acquisition mode, where a MS survey scan was used to automatically select multicharged peptides for further MS/MS fragmentation. From each survey scan up to three most intense peptides were selected for fragmentation. MS/MS collision energy was dependent on precursor ion mass and charge state. A reference spectrum was collected at every 30 
seconds from the Glu-fibrinopeptide B $(785.8426 \mathrm{~m} / \mathrm{z})$, introduced via a reference sprayer.

The raw mass spectral data was processed with ProteinLynx Global Server 2.2.5 (Waters Corporation, Milford, Massachusetts, USA) to generate peaklist files. The processing parameters with respect to noise reduction, de-isotoping, and centroiding were as follows: background subtract type: normal; background threshold: $20 \%$; background polynomial: 5; smoothing type: Savitzky-Golay. Deisotoping and centroiding in MS mode: medium; threshold: 3\%; centroid top: $80 \%$. Deisotoping and centroiding in MS/MS mode: deisotoping type: medium; threshold: $1 \%$. The mass accuracy of the spectra was further corrected by using the reference spectra from Glu-fibrinopeptide B.

The resulting peaklist files were searched against a locally curated protein sequence database (1870 entries) of S. uberis 0140J (GenBank Accession AM946015) using Mascot ver. 2.2 (Matrix Science, London, UK). Precursor and fragment ion mass tolerance were set to +/- 200 ppm and +/- 0.2 Da respectively. Oxidation of methionine residue was allowed as a variable modification. Trypsin specificity was used for allowing for 1 missed cleavage. The interpretation and presentation of MS/MS data was performed according to published guidelines ${ }^{39}$. Decoy database searches were performed with a randomised sequence database of $S$. uberis $0140 \mathrm{~J}$ and revealed a false discovery rate for peptide matches above an identity threshold of less than $4 \%$. The score threshold for acceptance of a positive protein identification was $\geq 50$ and with a requirement of a minimum of two unique peptide per protein hits.

\section{Results}




\section{Characterization of S. uberis SrtA mutant}

A SrtA mutant was isolated containing the $808 \mathrm{bp}$, ISS1 element inserted between base pairs 248 and 249 of $s r t A$ in the reverse orientation. A translation product of the first 82 residues of the 252 amino acids of SrtA was predicted which extended 18 residues into the ISS1 element before a stop codon was reached. Based on homology with known SrtA protein sequences, including those from the $S$. aureus and Streptococcus pyogenes, the predicted product did not contain the active site domain of SrtA (Fig. 1). Sequence analysis revealed that the catalytic site of S. uberis SrtA most likely lies between residues 84-252. The SrtA deficient mutant showed no differences in colony morphology or growth rates in Todd Hewitt (THB), brain heart infusion broth (BHI) or raw bovine milk in comparison with the wild-type strain (data not shown).

\section{Analysis of wild type and SrtA deficient Streptococcus uberis cell wall proteomes under different growth conditions}

To determine which proteins were likely to be attached to the cell wall by SrtA, stringently washed cell wall preparations were generated from the wild type and SrtA mutant strains. Cell wall derived peptides were obtained from both exponential $\left(\mathrm{OD}_{550 \mathrm{~nm}}\right.$ $=0.6)$ and stationary $\left(\mathrm{OD}_{550 \mathrm{~nm}}>1\right)$ phases of growth and from two different growth media (THB and $\mathrm{BHI}$ ) and subjected to reverse-phase LCMS/MS for identification.

Each protein from wild-type S. uberis identified as per the defined criteria (Materials and methods) was subjected to further analysis (Supplementary Tables 1 and 2) and compared with a similar data set generated from cell wall peptides of the SrtA mutant under the same growth conditions. 
Cell wall fractions from wild type $S$. uberis grown in either $\mathrm{THB}$ or $\mathrm{BHI}$ media yielded a total of 17 and 13 protein identities, respectively (Supplementary Tables 1 and 2). The total number of unique proteins identified from the growth conditions was relatively limited (20 proteins), which can probably be attributed to the stringent conditions used in the production of the cell wall fractions.

The amino acid sequence of each identified protein was analysed for typical characteristics of SrtA anchored substrates. Of the proteins detected in the wild type strain, nine showed typical characteristics of SrtA anchored proteins; i.e. an LPXTG-like motif, the presence of a signal peptide and regions of C-terminal hydrophobicity (Table 1). The presence of these proteins within the corresponding sample from the SrtA mutant (Supplementary Tables 1 and 2) was also determined. Of the putative SrtA anchored substrates only one, sub0145, was detected in any of the samples generated from the SrtA mutant strain, grown in BHI media. In this case, the SrtA mutant samples yielded 5 peptides compared to 26 unique peptide matches from the equivalent wild type fractions (Supplementary Table 2).

Two putative SrtA substrate proteins were identified exclusively in extracts from THBgrown stationary phase cultures; a predicted subtilase-like serine protease (sub0826) and collagen-like protein (sub1095). Both proteins showed sequence similarities to other proteins known to be anchored in streptococci. In each case, three and two peptides respectively were identified for these proteins (representing coverage of 1.9 and $4.1 \%$, respectively of the total sequence). The low prevalence of peptides from each of these proteins may suggest their low abundance under the growth conditions tested, however, neither was identified in any SrtA mutant derived sample. 
Four of the putative SrtA substrates (sub0135, sub0826, sub1154 and sub1370) did not possess the typical LPXTG penta-peptide anchoring motif. However, in each case a hexa-peptide (LPXXXD/E) showing similarity to sorting motifs from other CDSs of streptococci was evident (Table 2). One protein, sub1370 identified as a zinc carboxypeptidase, displayed all the typical characteristics of an anchored protein, but possessed an anchoring motif of LPALAD. This protein was detected in samples generated under every growth condition tested and was only present in wild-type fractions and never observed in the SrtA mutant fractions. Furthermore, multiple peptides from this protein were detected (covering between 18 and $27 \%$ of the total coding sequence possibly indicating a high prevalence of this protein. The remaining five putative sortase substrates (sub0207, sub0241, sub0145, sub0888, sub1730) possessed 'classical' LPXTG or LPXAG motifs; in four of these cases the amino acid found in position 6 was acidic (D or E).

\section{Detection of the proteins sub0826, sub1154 and sub1370 in concentrated culture supernatants of wild type and the SrtA deficient mutant}

Rabbit antisera directed against sub0826, sub1154 or sub1370 were used to detect the presence of these proteins in concentrated culture supernatants of S. uberis $0140 \mathrm{~J}$ and the SrtA mutant. The proteins corresponding to sub0826, sub1154 and sub1370 were detected in far greater abundance in the growth media obtained from the SrtA mutant (Fig. 2), however in each case a trace of the full length protein was detected in culture supernatant from the wild type strain.

\section{Discussion}


In this study, we demonstrate the utility of a method of stringent cell wall isolation coupled with LCMS/MS to analyse strains of $S$. uberis with and without sortase A (SrtA). This enabled identification of nine proteins that were specifically associated with wild type cell walls; any or all of which may contribute to the interactions between $S$. uberis and its surrounding environment.

Unlike many other streptococci, S. uberis 0140J has a single sortase (sub0881; sitA) within its genome ${ }^{34}$. Analysis of this revealed an $\mathrm{N}$-terminal region of hydrophobic amino acids containing both a membrane anchoring motif and a signal peptide in addition to the conserved sortase signature (TLXTC) containing the essential catalytic cysteine residue 40. These features are indicative of a secreted protein that is retained at the cytoplasmic membrane. Protein sequence comparison by BLASTP showed the sequence had the highest sequence identity with SrtA from two other pyogenic streptococci; Streptococcus equi subspecies zooepidemicus (79\%) and S. pyogenes (71\%) (Fig.1). In contrast, the sequence similarity to SrtA from S. aureus is approximately $31 \%$.

To identify proteins that were likely to be anchored by SrtA, we focused on the analysis of proteins which were strongly associated with the bacterial peptidoglycan of the wild type strain. The harsh purification process that was used to enrich cell wall fractions via differential centrifugation and prolonged heating in the presence of SDS has been previously demonstrated to significantly increase the numbers of identified, covalentlyanchored proteins ${ }^{29,30}$. In our study, we identified 9 proteins likely to be anchored by sortase within a total of 20 identified proteins. Initially, peptides isolated from cell wall fractions from exponentially growing and stationary phase cultures from each growth medium were analysed by LCMS/MS separately in order to maximise the potential for protein identification induced from the different growth conditions. However, no proteins 
were identified exclusively during early phases of growth. Due to the limited number of spectra obtained for analysis, which can probably be attributed to the stringent conditions used to obtain the purified cell walls, the peaklists generated for each strain grown in either THB or $\mathrm{BHI}$ medium at different stages of growth were combined. $\mathrm{A}$ decoy-database search allowed estimation of a false discovery rate of less than $4 \%$ of the peptides above identity scores. By limiting positive identities to those with MASCOT Mowse scores higher than 50 and only analysing protein identities with more than two unique peptide hits, the confidence in positive identification for these proteins was significantly higher. Furthermore, by analysing each protein identity for typical characteristics of SrtA anchored proteins and cross referencing for the absence of these proteins in cell wall fractions from the SrtA mutant, we could confirm the presence of nine SrtA anchored proteins.

Most of the identified proteins were present on cell walls from bacteria grown in both THB and $\mathrm{BHI}$ media, with two exceptions; the subtilase-like serine protease, sub0826 and the collagen-like protein, sub1095. These were only detected on cell walls from bacteria grown in THB. It is possible these proteins are specifically regulated; induced in THB or repressed in $\mathrm{BHI}$.

The list of SrtA-anchored proteins detected and identified during this investigation correlated well with that predicted during bioinformatic annotation of the completed genome sequence ${ }^{34}$. The prediction identified nine CDSs with characteristics consistent with SrtA anchored substrates and a further four CDSs that showed strong homology to proteins known to be anchored in other streptococci. The latter group, however, did not contain typical (LPXXG) anchor motifs and were considered to be possible rather than probable SrtA anchored sequences. Of the thirteen CDSs identified three (sub0164, 
sub0764 and sub1739) were considered pseudogenes and one (sub0348) was considered to be a gene fragment. Eight of the nine remaining predicted SrtA anchored substrates were identified in the present investigation. The failure to detect one putative cell wall anchored protein identified from the genome as sub0241 may be due to the low abundance of this protein in the fractions analysed, or possibly due to lack of expression under the in vitro growth conditions used. Not unsurprisingly no peptides corresponding to the pseudogenes or the gene fragment were detected.

This investigation therefore confirmed the likely cell wall anchoring of those CDSs with atypical sorting motifs identified during genome annotation (sub0135, sub0826 and sub1154). Additionally, the present study identified a further protein likely to be anchored by SrtA (sub1370) that was not identified by bioinformatics.

In the absence of the SrtA enzyme, proteins normally anchored at the surface are likely to be released directly into the bacterial growth media. Indeed, the selective release of three such proteins (all putatively identified as proteases) containing non-typical anchoring motifs (sub0826, sub1154 and sub1370) was confirmed by immunoblotting of concentrated culture supernatants; providing further evidence that despite the absence of an LPXTG/LPXXG motif these proteins were anchored to the bacterial cell by SrtA.

Of the nine proteins identified as SrtA anchored in this study, a number show similarity to known streptococcal virulence determinants or known cell wall anchored proteins. The putative fructan beta-fructosidase FruA (sub0135), shares 55\% similarity at the protein level with a fructan hydrolase of Streptococcus mutans, an enzyme required for the transport or metabolism of sucrose ${ }^{41}$. Localisation of this enzyme has found it to be either secreted ${ }^{42}$ or anchored to the cell wall ${ }^{43}$ depending upon growth conditions. It is 
thought that the enzyme is anchored to the cell wall and released in response to an environmental stimulus, much like the anchored protein WapA of S. mutans ${ }^{44}$. The product of the CDS sub1154 shows similarity to the C5a peptidase of S. pyogenes (34\% similar at the protein level), another cell wall anchored virulence determinant of streptococci ${ }^{45}$. This enzyme is also released from the cell wall with the resulting fragment capable of inhibiting the recruitment of phagocytes to the site of infection ${ }^{46}$.

The lactoferrin binding protein (Lbp, sub0145) has been identified as a possible virulence determinant of $S$. uberis and has been demonstrated as able to bind bovine lactoferrin ${ }^{47}$. The concentration of this iron-chelating compound increases in the mammary gland during infection ${ }^{48}$ as part of the innate response to infection. Whilst iron limitation is known to have an anti-microbial effect on some mastitic pathogens, including E. coli and S. aureus, it appears to have little effect on S. uberis ${ }^{49,50 .}$

Analysis of the anchoring motifs of each of the covalently anchored proteins revealed the presence of the classical LPXTG motif (or LPXAG) in five of the anchored proteins (sub0145, sub0207, sub0888, sub1095 and sub1730) and the presence of an alternate anchoring motif of LPXXXD in the remaining anchored proteins (sub0135, sub0826, sub1154 and sub1370). Early reports of putative anchoring motifs by Fischetti et al ${ }^{51}$ reported highly conserved hexa-peptide sequences at the C-terminal end of 11 known surface proteins of Gram positive cocci with a consensus sequence of LPXTGE. Upon identification of the SrtA enzyme in $S$. aureus ${ }^{7}$ it became apparent that the conserved anchoring motif sequence for many Gram positive bacteria was LPXTG. Confirmation that this motif was favoured for enzymatic cleavage was tested by substituting individual amino acids into the a penta-peptide LPTEG library and measuring for kinetically favoured substrates ${ }^{52}$. 
Within Gram positive bacteria, the majority of proteins anchored by SrtA appear to conform to the LPXTG motif, however a number of variations of the anchoring sequences have been reported ${ }^{1,52}$ with most reporting variation by single amino acid residues in the latter half of the sortase cleavage site. However, SrtA from Clostridium difficile recognises motifs containing SPXTG or PPXTG ${ }^{9}$, whilst that from Lactobacillus plantarum recognises LPQTXE as a motif ${ }^{19,53}$.

In streptococcal species most anchored proteins conform to the traditional LPXTG motif; however, there are a number of exceptions. Apart from the four proteins with alternate anchoring motifs in S. uberis identified in this study, a number are also found in S. agalactiae, S. equi, S. pyogenes and one in S. pnemoniae (Table 2). One common feature to most of these proteins is an LPXTXD/E motif which suggests another kinetically favoured anchoring motif exists when the $5^{\text {th }}$ residue has been modified from the traditional glycine. It appears that the conformation of the protein at this region, or indeed the proximity of acidic residues at position 6 of this motif may be equally important for cell wall anchoring by the SrtA enzyme in the absence of the LPXTG motif. The implication of this finding is that some SrtA anchored proteins of other bacterial species may have been disregarded, particularly during comparisons conducted exclusively in silico. For example, analysis of the $S$. uberis genome for proteins with an $\mathrm{N}$-terminal signal peptide, a carboxy terminal LPXXG motif, a C-terminal hydrophobic region and a tail of charged amino acid residues identifies 9 potential SrtA substrates containing LPXTG with a further two possessing LPXAG motifs. Each of these proteins is recognised as an anchored protein by the cellular localization program PSORT ${ }^{54}$. Additionally, the proteins sub0135, sub0826 and sub1154 are identified by PSORT as cell wall anchored, based on solely on similarity with other known SrtA anchored 
proteins. The S. uberis carboxypeptidase sub1370 is not identified, however, using PSORT and is not identified using other programs designed to identify cell wall attached proteins ${ }^{4,19}$. It was only the direct experimental comparison of cell wall peptides from wild-type and the SrtA isogenic mutant in this study that identified this protein as covalently anchored. Further analysis of the S. uberis genome searching for other LPXXXD/E motifs and proteins with typical sortase anchoring characteristics did not reveal any further potentially SrtA-anchored proteins.

In conclusion, the ability to obtain highly purified peptidoglycan enriched fractions of the S. uberis cell walls and comparison of the protein repertoires present in the wild-type and SrtA deficient strains has allowed the identification of nine SrtA cell wall anchored proteins of $S$. uberis. The identification and analysis of the anchoring motifs of these proteins identifies two anchoring motifs, the traditional LPXTG and the alternate LPXXXD motifs and highlights the potential for the presence of alternate cell wall anchoring motifs, either LPXTXD/E or LPXXXD for this and a number of other streptococcal species. 
S.aureus

S.uberis

S.equi

S.pyogenes

S.mutans

S.agal

S.aureus

S. uberis

S.equi

S.pyogenes

S.mutans

S.agal

S.aureus

S.uberis

S.equi

S.pyogenes

S.mutans

S.agal

S.aureus

S.uberis

S.equi

S.pyogenes

S.mutans

S.agal

S.aureus

S. uberis

S.equi

S.pyogenes

S.mutans

S.agal

\begin{abstract}
MKKWTNR----------LMT IAGVVL I LVAAYLFAKPH I DNYLHDKDKDEK I EQY DKNV MAESRRRKKGKSTFSDKLRSFLAVILLIVGLLLLFNKP IRNTLIAWNSNRYQVQHVTKDT ------------MSFARG I LVVLLLI I GLALLFNKP I RNTLIAWNSNKYQVTKVSKKT MVKKQKRRKIKS--MSWARKLLIAVLLI LGLALLFNKPIRNTLIARNSNKYQVTKVSKKQ MKKERQSRKKRS----FLRTFLP I LLLVI GLAL IFNTP I RNAL I AWNTNRYQVSNVSKKD MRNKKKS HGFFN----FVRWLLVVLLI IVGLALVFNKPI RNAF IAHQSNHYQ I SRVSKKT SP/TM Region
\end{abstract}

\section{Figure 1: Sortase A sequence alignment}

Sequence alignment of the sortase enzymes from Streptococcus uberis (S. uberis; Accession number YP_002562210) with Staphylococcus aureus (S. aureus; Accession number YP_001333460) as well as the most closely related bacterial species according to BLASTP comparisons including Streptococcus equi subspecies zooepidemicus (S. equi; Accession number YP_002744471), Streptococcus pyogenes (S. pyogenes; Accession number NP_269304), Streptococcus mutans (S. mutans; Accession number NP_721500), and Streptococcus agalactiae (S. agalactiae; Accession number YP_329677) performed using ClustalW. Conserved amino acids proposed to be important in the active site of the enzyme are highlighted in red and the equivalent catalytic domains are highlighted in grey. The number of amino acid residues is indicated at the end of each sequence and the putative signal peptide and transmembrane region at the $\mathrm{N}$-terminal region of the proteins is marked (SP/TM region). The amino acids highlighted in red are conserved in sortase enzymes from Gram-positive bacteria, including the conserved signature motif of the enzyme (TLXTC) which contains the catalytic cysteine residue that is essential for the cleavage of the scissile threonine-glycine bond in substrate proteins ${ }^{40}$. 


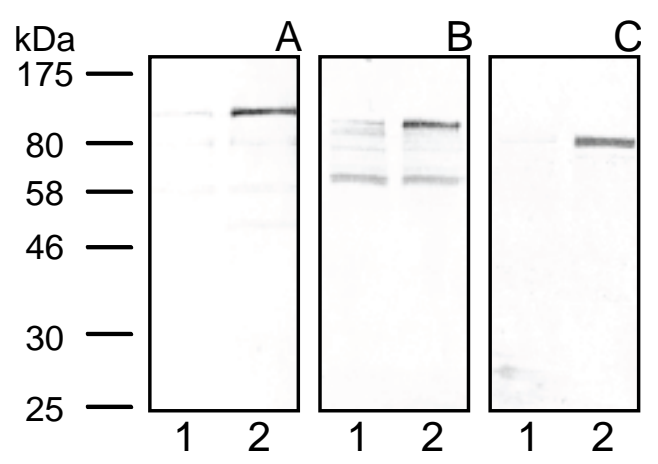

Figure 2: Identification of Sub0826, Sub1154 and Sub1370 from extracts of Streptococcus uberis 0140J.

Immunoblots of protein extracts from $S$. uberis $0140 \mathrm{~J}$ and the srtA mutant probed with rabbit antisera generated against Sub0826 (A), Sub1154 (B) and Sub1370 (C). Precipitated media extracts from 0140J (lane 1) and srtA mutant (lane 2) were analysed respectively, with molecular weight standards indicated. 


\begin{tabular}{|c|c|c|c|c|c|c|c|c|c|c|c|}
\hline & & & & \multicolumn{5}{|c|}{ Combined THB growth phases } & \multicolumn{3}{|c|}{ Combined BHI growth phases } \\
\hline Gene $^{a}$ & Protein annotation & $\begin{array}{l}\text { Putative } \\
\text { sortase } \\
\text { anchor }\end{array}$ & $\begin{array}{c}\text { Molecular } \\
\text { mass } \\
(\text { Da })^{b}\end{array}$ & $\begin{array}{l}\text { MASCOT } \\
\text { score }\end{array}$ & $\begin{array}{c}\text { No. of } \\
\text { peptides } \\
\text { matched }^{c}\end{array}$ & $\begin{array}{c}\text { Total } \\
\text { spectral } \\
\text { counts }\end{array}$ & $\begin{array}{c}\text { Coverage } \\
(\%)^{d}\end{array}$ & $\begin{array}{l}\text { MASCOT } \\
\text { score }\end{array}$ & $\begin{array}{c}\text { No. of } \\
\text { peptides } \\
\text { matched }^{c}\end{array}$ & $\begin{array}{c}\text { Total } \\
\text { spectral } \\
\text { counts }\end{array}$ & $\begin{array}{c}\text { Coverage } \\
(\%)^{d}\end{array}$ \\
\hline sub0135 & $\begin{array}{l}\text { FruA: Putative } \\
\text { fructan beta- } \\
\text { fructosidase } \\
\text { precursor }\end{array}$ & LPMTSDS & 142,956 & 570 & 10 & 11 & 12.5 & 1323 & 18 & 26 & 23.4 \\
\hline sub0145 & $\begin{array}{l}\text { Lbp: Putative } \\
\text { lactoferrin binding } \\
\text { protein }\end{array}$ & LPSTGDK & 57,829 & 1851 & 23 & 51 & 37.4 & 3909 & 26 & 93 & $48.9^{e}$ \\
\hline sub0207 & $\begin{array}{l}\text { Putative surface } \\
\text { anchored protein }\end{array}$ & LPMAGER & 53,765 & 139 & 3 & 4 & 7.8 & 261 & 5 & 6 & 13.6 \\
\hline sub0826 & $\begin{array}{l}\text { Putative surface } \\
\text { anchored subtilase } \\
\text { family protein }\end{array}$ & LPETRDS & 168,468 & 50 & 3 & 3 & 1.9 & - & - & - & - \\
\hline sub0888 & $\begin{array}{l}\text { Putative surface } \\
\text { anchored protein }\end{array}$ & LPPTGSQ & 29,230 & 256 & 2 & 4 & 18.0 & 313 & 2 & 4 & 18.0 \\
\hline sub1095 & $\begin{array}{l}\text { SclB: Putative } \\
\text { collagen like surface } \\
\text { anchored protein }\end{array}$ & LPSTGDK & 47,642 & 131 & 2 & 3 & 4.1 & & - & - & - \\
\hline sub1154 & $\begin{array}{l}\text { ScpA: Putative C5a } \\
\text { peptidase precursor }\end{array}$ & LPKTVDS & 127,957 & 165 & 6 & 7 & 6.0 & 414 & 11 & 13 & 14.4 \\
\hline sub1370 & $\begin{array}{l}\text { Putative zinc- } \\
\text { carboxypeptidase }\end{array}$ & LPALADG & 116,563 & 3268 & 17 & 55 & 26.7 & 1220 & 18 & 25 & 22.3 \\
\hline sub1730 & $\begin{array}{l}\text { Putative surface } \\
\text { anchored protein }\end{array}$ & LPSTGED & 40,439 & 387 & 4 & 9 & 13.8 & 232 & 4 & 5 & 13.8 \\
\hline
\end{tabular}

Table 1: Sortase anchored proteins identified in cell wall extracts of S. uberis $0140 \mathrm{~J}$ cultured in THB or BHI media

${ }^{a}$ Gene and protein annotation according to the genomic sequence of Streptococcus uberis $0140 \mathrm{~J} 34$

b Theoretical molecular mass values for protein precursors obtained from Artemis database from the Wellcome Trust Sanger Institute (http://www.sanger.ac.uk/)

$c$ Number of unique peptide hits for each protein

dPercentage of protein sequence covered by experimentally detected peptides 
${ }^{e} 5$ peptides identified in the SrtA mutant cell wall fraction. With this exception, none of the other proteins were detected in cell wall samples from the SrtA mutant 


\begin{tabular}{|c|c|c|c|c|c|}
\hline $\begin{array}{l}\text { Bacterial } \\
\text { species }\end{array}$ & Gene $^{a}$ & Protein annotation & $\begin{array}{l}\text { Atypical } \\
\text { sorting } \\
\text { motif }\end{array}$ & $\begin{array}{l}\text { Protein } \\
\text { reference }\end{array}$ & Reference \\
\hline S.uberis & $\begin{array}{l}\text { FruA; } \\
\text { sub0135 }\end{array}$ & $\begin{array}{l}\text { Putative fructan beta-fructosidase } \\
\text { precursor }\end{array}$ & LPMTSDS & CAR40555 & This study \\
\hline S. uberis & $\begin{array}{l}\text { Lbp; } \\
\text { sub0145 }\end{array}$ & $\begin{array}{l}\text { Putative surface anchored } \\
\text { subtilase family protein }\end{array}$ & LPETRDS & CAR41854 & This study \\
\hline S. uberis & $\begin{array}{l}\text { ScpA; } \\
\text { sub1154 }\end{array}$ & Putative C5a peptidase precursor & LPKTVDS & CAR42550 & This study \\
\hline S. uberis & sub1370 & Putative zinc-carboxypeptidase & LPALADG & CAR42963 & This study \\
\hline S. agalactiae & SAG0416 & Streptococcal C5a peptidase & LPSTSDR & AAM99322 & 55 \\
\hline S. agalactiae & SAG1333 & 5'-nucleotidase family protein & LPKTNSE & AAN00204 & 55 \\
\hline $\begin{array}{l}\text { S. equi } \\
\text { subspecies } \\
\text { zooepidemicus }\end{array}$ & SZO_10150 & $\begin{array}{l}\text { Putative cell surface-anchored } \\
\text { C5A peptidase precursor }\end{array}$ & LPKTSEK & CAW99349 & 56 \\
\hline $\begin{array}{l}\text { S. equi } \\
\text { subspecies } \\
\text { equi }\end{array}$ & $\begin{array}{l}\text { FneC; } \\
\text { SEQ_1606 }\end{array}$ & $\begin{array}{l}\text { Putative collagen-binding } \\
\text { collagen-like cell surface- } \\
\text { anchored protein }\end{array}$ & LPKTNDT & CAW94597 & 56 \\
\hline $\begin{array}{l}\text { S. equi } \\
\text { subspecies } \\
\text { equi }\end{array}$ & $\begin{array}{l}\text { FneE; } \\
\text { SEQ_0555 }\end{array}$ & $\begin{array}{l}\text { Putative collagen and fibronectin- } \\
\text { binding cell surface-anchored } \\
\text { protein }\end{array}$ & LPRTNEA & CAW92812 & 56 \\
\hline $\begin{array}{l}\text { S. equi } \\
\text { subspecies } \\
\text { equi }\end{array}$ & SEQ_0256 & $\begin{array}{l}\text { Putative cell surface-anchored } \\
\text { protein }\end{array}$ & LPATADT & CAW92309 & 56 \\
\hline S. pneumoniae & spr1771 & Subtilisin-like serine protease & LPNTSEN & AAL00574 & 57 \\
\hline S. pyogenes & $\begin{array}{l}\text { ScpA; } \\
\text { M6 Spy } 1718\end{array}$ & C5a peptidase & LPTTNDK & AAT87853 & 58 \\
\hline S. pyogenes & $\begin{array}{l}\text { Grab; } \\
\text { spyM18_1369 }\end{array}$ & $\begin{array}{l}\text { Protein G-related alpha 2M- } \\
\text { binding protein (GRAB) }\end{array}$ & LPTTSEE & AAL97965 & 59 \\
\hline
\end{tabular}

Table 2: Atypical sortase anchoring motifs in Streptococcal species

${ }^{a}$ Gene and protein annotation reference according to the NCBI protein database 


\begin{tabular}{|c|c|c|c|c|c|c|c|c|c|}
\hline Gene $^{a}$ & Protein annotation & $\begin{array}{l}\text { Molecular } \\
\text { mass } \\
(\mathrm{Da})^{b} \\
\end{array}$ & $\begin{array}{l}\text { MASCOT } \\
\text { Score }\end{array}$ & $\begin{array}{l}\text { Unique } \\
\text { peptides } \\
\text { matched }\end{array}$ & $\begin{array}{l}\text { Total } \\
\text { spectral } \\
\text { counts } \\
\end{array}$ & $\begin{array}{l}\text { Coverage } \\
(\%)^{c}\end{array}$ & $\begin{array}{l}\text { Putative } \\
\text { C-terminal } \\
\text { anchor }\end{array}$ & $\begin{array}{l}\text { Signal } \\
\text { peptide }\end{array}$ & $\begin{array}{l}\text { Presence in } \\
\text { SrtA mutant } \\
\text { fraction }\end{array}$ \\
\hline sub1370 & Putative zinc carboxypeptidase & 116,563 & 3268 & 17 & 55 & 26.7 & LPALADG & Present & No \\
\hline sub0145 & Lactoferrin binding protein & 57,829 & 1851 & 23 & 51 & 37.4 & LPSTGDK & Present & No \\
\hline sub0135 & $\begin{array}{l}\text { Putative fructan beta-fructosidase } \\
\text { precursor }\end{array}$ & 142,956 & 570 & 10 & 11 & 12.5 & LPMTSDS & Present & No \\
\hline sub1730 & Putative surface anchored protein & 40,439 & 387 & 4 & 9 & 13.8 & LPSTGED & Present & No \\
\hline sub1717 & $\begin{array}{l}\text { Putative glycine-betaine-binding } \\
\text { permease protein }\end{array}$ & 63,184 & 276 & 5 & 6 & 11.2 & None & Absent & Yes \\
\hline sub0888 & Putative surface anchored protein & 29,230 & 256 & 2 & 4 & 18.0 & LPPTGSQ & Present & No \\
\hline sub1326 & $\begin{array}{l}\text { C4-dicarboxylate anaerobic carrier } \\
\text { protein }\end{array}$ & 53,657 & 237 & 3 & 6 & 7.2 & None & Present & Yes \\
\hline sub0750 & $\begin{array}{l}\text { Putative fructose-specific } \\
\text { phosphotransferase system (PTS), } \\
\text { IIABC component }\end{array}$ & 66,892 & 234 & 3 & 5 & 6.2 & None & Absent & Yes \\
\hline sub1154 & Putative C5a peptidase precursor & 127,958 & 165 & 6 & 7 & 6.0 & LPKTVDS & Present & No \\
\hline sub1328 & Arginine deiminase & 46,336 & 151 & 3 & 3 & 7.8 & None & Absent & Yes \\
\hline sub0799 & $\begin{array}{l}\text { Putative lactose-specific } \\
\text { phosphotransferase system (PTS), IIBC } \\
\text { component } 2\end{array}$ & 60,633 & 142 & 2 & 3 & 4.1 & None & Absent & Yes \\
\hline sub0207 & Putative surface anchored protein & 53,765 & 139 & 3 & 4 & 7.8 & LPMAGER & Present & No \\
\hline sub1095 & Collagen like surface anchored protein & 47,642 & 131 & 2 & 3 & 4.1 & LPSTGDK & Present & No \\
\hline sub1357 & Putative membrane protein & 45,516 & 109 & 2 & 3 & 7.7 & None & Present & Yes \\
\hline sub0063 & Aldehyde-alcohol dehydrogenase 2 & 96,479 & 93 & 2 & 2 & 4.0 & LPLVKDM & Absent & Yes \\
\hline sub0533 & $\begin{array}{l}\text { Sugar phosphotransferase system (PTS), } \\
\text { IIC component }\end{array}$ & 47,152 & 84 & 2 & 4 & 4.3 & None & Absent & Yes \\
\hline sub0826 & $\begin{array}{l}\text { Putative surface anchored subtilase } \\
\text { family protein }\end{array}$ & 168,468 & 50 & 3 & 3 & 1.8 & LPETRDS & Present & No \\
\hline
\end{tabular}

\section{Supplementary Table 1: Summary of all identified proteins in cell wall extracts of S. uberis $0140 \mathrm{~J}$ cultured in THB media}

a Gene and protein annotation according to the genomic sequence of Streptococcus uberis $0140 \mathrm{~J} 34$

b Theoretical molecular mass values for protein precursors obtained from Artemis database from the Wellcome Trust Sanger Institute (http://www.sanger.ac.uk/)

c Percentage of protein sequence covered by experimentally detected peptides 


\begin{tabular}{|c|c|c|c|c|c|c|c|c|c|}
\hline Gene $^{a}$ & Protein annotation & $\begin{array}{l}\text { Molecular } \\
\text { mass } \\
(\text { Da })^{b}\end{array}$ & $\begin{array}{l}\text { MASCOT } \\
\text { Score }\end{array}$ & $\begin{array}{l}\text { Unique } \\
\text { peptides } \\
\text { matched }\end{array}$ & $\begin{array}{l}\text { Total } \\
\text { spectral } \\
\text { counts }\end{array}$ & $\begin{array}{l}\text { Coverage } \\
(\%)^{c}\end{array}$ & $\begin{array}{l}\text { Putative } \\
\text { C-terminal } \\
\text { anchor }\end{array}$ & $\begin{array}{l}\text { Signal } \\
\text { peptide }\end{array}$ & $\begin{array}{l}\text { Presence in } \\
\text { SrtA mutant } \\
\text { fraction }\end{array}$ \\
\hline sub0145 & Lactoferrin binding protein & 57,829 & 3909 & 26 & 93 & 48.9 & LPSTGDK & Present & Yes $^{\mathbf{d}}$ \\
\hline sub0135 & $\begin{array}{l}\text { Putative fructan beta-fructosidase } \\
\text { precursor }\end{array}$ & 142,956 & 1323 & 18 & 26 & 23.4 & LPMTSDS & Present & No \\
\hline sub1370 & Putative zinc carboxypeptidase & 116,563 & 1220 & 18 & 25 & 22.3 & LPALADG & Present & No \\
\hline sub1154 & Putative C5a peptidase precursor & 127,958 & 414 & 11 & 13 & 14.4 & LPKTVDS & Present & No \\
\hline sub0888 & Putative surface anchored protein & 29,230 & 313 & 2 & 4 & 18.0 & LPPTGSQ & Present & No \\
\hline sub0207 & Putative surface anchored protein & 53,765 & 261 & 5 & 6 & 13.6 & LPMAGER & Present & No \\
\hline sub1730 & Putative surface anchored protein & 40,439 & 232 & 4 & 5 & 13.8 & LPSTGED & Present & No \\
\hline sub0655 & Enolase & 47,308 & 225 & 4 & 4 & 12.6 & None & Absent & Yes \\
\hline sub0750 & $\begin{array}{l}\text { Putative fructose-specific } \\
\text { phosphotransferase system (PTS), IIABC } \\
\text { component }\end{array}$ & 66,892 & 209 & 4 & 4 & 7.7 & None & Absent & Yes \\
\hline sub1717 & $\begin{array}{l}\text { Putative glycine-betaine-binding permease } \\
\text { protein }\end{array}$ & 63,184 & 148 & 3 & 3 & 7.0 & None & Absent & Yes \\
\hline sub1328 & Arginine deiminase & 46,336 & 91 & 2 & 2 & 5.6 & None & Absent & Yes \\
\hline sub0604 & Elongation factor $\mathrm{Tu}$ & 43,914 & 74 & 2 & 2 & 7.3 & LPAGTEM & Absent & Yes \\
\hline sub1543 & $\begin{array}{l}\text { Putative sucrose specific } \\
\text { phosphotransferase system (PTS) IIABC } \\
\text { component }\end{array}$ & 66,128 & 60 & 2 & 2 & 3.2 & None & Absent & No \\
\hline
\end{tabular}

Supplementary Table 2: Summary of all identified proteins in cell wall extracts of S. uberis 0140J cultured in BHI media

a Gene and protein annotation according to the genomic sequence of Streptococcus uberis $0140 \mathrm{~J} 34$

b Theoretical molecular mass values for protein precursors obtained from Artemis database from the Wellcome Trust Sanger Institute (http://www.sanger.ac.uk/)

c Percentage of protein sequence covered by experimentally detected peptides

d 5 peptides identified in the SrtA mutant cell wall fraction 


\section{References}

1. Navarre, W. W.; Schneewind, O., Surface proteins of gram-positive bacteria and mechanisms of their targeting to the cell wall envelope. Microbiol Mol Biol Rev 1999, 63, (1), 174-229.

2. Galperin, M. Y.; Koonin, E. V., Searching for drug targets in microbial genomes. Curr Opin Biotechnol 1999, 10, (6), 571-8.

3. Grandi, G., Antibacterial vaccine design using genomics and proteomics. Trends Biotechnol 2001, 19, (5), 181-8.

4. Janulczyk, R.; Rasmussen, M., Improved pattern for genome-based screening identifies novel cell wall-attached proteins in gram-positive bacteria. Infect Immun 2001, 69, (6), 4019-26.

5. Scott, J. R.; Barnett, T. C., Surface proteins of gram-positive bacteria and how they get there. Annu Rev Microbiol 2006, 60, 397-423.

6. Comfort, D.; Clubb, R. T., A comparative genome analysis identifies distinct sorting pathways in gram-positive bacteria. Infect Immun 2004, 72, (5), 2710-22.

7. Mazmanian, S. K.; Liu, G.; Ton-That, H.; Schneewind, O., Staphylococcus aureus sortase, an enzyme that anchors surface proteins to the cell wall. Science 1999, 285, (5428), 760-3.

8. Dramsi, S.; Trieu-Cuot, P.; Bierne, H., Sorting sortases: a nomenclature proposal for the various sortases of Gram-positive bacteria. Res Microbiol 2005, 156, (3), 289-97.

9. Pallen, M. J.; Lam, A. C.; Antonio, M.; Dunbar, K., An embarrassment of sortases - a richness of substrates? Trends Microbiol 2001, 9, (3), 97-102.

10. Mazmanian, S. K.; Ton-That, H.; Schneewind, O., Sortase-catalysed anchoring of surface proteins to the cell wall of Staphylococcus aureus. Mol Microbiol 2001, 40, (5), 1049-57.

11. Bender, M. H.; Weiser, J. N., The atypical amino-terminal LPNTGcontaining domain of the pneumococcal human IgA1-specific protease is required for proper enzyme localization and function. Mol Microbiol 2006, 61, (2), 526-43.

12. Rigel, N. W.; Braunstein, M., A new twist on an old pathway--accessory Sec [corrected] systems. Mol Microbiol 2008, 69, (2), 291-302.

13. Navarre, W. W.; Schneewind, O., Proteolytic cleavage and cell wall anchoring at the LPXTG motif of surface proteins in gram-positive bacteria. Mol Microbiol 1994, 14, (1), 115-21.

14. Schneewind, O.; Model, P.; Fischetti, V. A., Sorting of protein A to the staphylococcal cell wall. Cell 1992, 70, (2), 267-81.

15. Perry, A. M.; Ton-That, H.; Mazmanian, S. K.; Schneewind, O., Anchoring of surface proteins to the cell wall of Staphylococcus aureus. III. Lipid II is an in vivo peptidoglycan substrate for sortase-catalyzed surface protein anchoring. $J$ Biol Chem 2002, 277, (18), 16241-8.

16. Race, P. R.; Bentley, M. L.; Melvin, J. A.; Crow, A.; Hughes, R. K.; Smith, W. D.; Sessions, R. B.; Kehoe, M. A.; McCafferty, D. G.; Banfield, M. J., Crystal structure of Streptococcus pyogenes sortase A: implications for sortase mechanism. J Biol Chem 2009, 284, (11), 6924-33.

17. Chung, J. W.; Ng-Thow-Hing, C.; Budman, L. I.; Gibbs, B. F.; Nash, J. H.; Jacques, M.; Coulton, J. W., Outer membrane proteome of Actinobacillus 
pleuropneumoniae: LC-MS/MS analyses validate in silico predictions. Proteomics 2007, 7, (11), 1854-65.

18. Rodriguez-Ortega, M. J.; Norais, N.; Bensi, G.; Liberatori, S.; Capo, S.; Mora, M.; Scarselli, M.; Doro, F.; Ferrari, G.; Garaguso, I.; Maggi, T.; Neumann, A.; Covre, A.; Telford, J. L.; Grandi, G., Characterization and identification of vaccine candidate proteins through analysis of the group A Streptococcus surface proteome. Nat Biotechnol 2006, 24, (2), 191-7.

19. Boekhorst, J.; de Been, M. W.; Kleerebezem, M.; Siezen, R. J., Genome-wide detection and analysis of cell wall-bound proteins with LPxTG-like sorting motifs. $J$ Bacteriol 2005, 187, (14), 4928-34.

20. Cole, J. N.; Ramirez, R. D.; Currie, B. J.; Cordwell, S. J.; Djordjevic, S. P.; Walker, M. J., Surface analyses and immune reactivities of major cell wallassociated proteins of group a streptococcus. Infect Immun 2005, 73, (5), 3137-46.

21. Gatlin, C. L.; Pieper, R.; Huang, S. T.; Mongodin, E.; Gebregeorgis, E.; Parmar, P. P.; Clark, D. J.; Alami, H.; Papazisi, L.; Fleischmann, R. D.; Gill, S. R.; Peterson, S. N., Proteomic profiling of cell envelope-associated proteins from Staphylococcus aureus. Proteomics 2006, 6, (5), 1530-49.

22. Hughes, M. J.; Moore, J. C.; Lane, J. D.; Wilson, R.; Pribul, P. K.; Younes, Z. N.; Dobson, R. J.; Everest, P.; Reason, A. J.; Redfern, J. M.; Greer, F. M.; Paxton, T.; Panico, M.; Morris, H. R.; Feldman, R. G.; Santangelo, J. D., Identification of major outer surface proteins of Streptococcus agalactiae. Infect Immun 2002, 70, (3), 1254-9.

23. Morsczeck, C.; Prokhorova, T.; Sigh, J.; Pfeiffer, M.; Bille-Nielsen, M.; Petersen, J.; Boysen, A.; Kofoed, T.; Frimodt-Moller, N.; Nyborg-Nielsen, P.; Schrotz-King, P., Streptococcus pneumoniae: proteomics of surface proteins for vaccine development. Clin Microbiol Infect 2008, 14, (1), 74-81.

24. Nandakumar, R.; Nandakumar, M. P.; Marten, M. R.; Ross, J. M., Proteome analysis of membrane and cell wall associated proteins from Staphylococcus aureus. J Proteome Res 2005, 4, (2), 250-7.

25. Taverna, F.; Negri, A.; Piccinini, R.; Zecconi, A.; Nonnis, S.; Ronchi, S.; Tedeschi, G., Characterization of cell wall associated proteins of a Staphylococcus aureus isolated from bovine mastitis case by a proteomic approach. Vet Microbiol 2007, 119, (2-4), 240-7.

26. Wright, A.; Wait, R.; Begum, S.; Crossett, B.; Nagy, J.; Brown, K.; Fairweather, N., Proteomic analysis of cell surface proteins from Clostridium difficile. Proteomics 2005, 5, (9), 2443-52.

27. Anderson, N. G.; Anderson, N. L., Twenty years of two-dimensional electrophoresis: past, present and future. Electrophoresis 1996, 17, (3), 443-53.

28. Cordwell, S. J., Technologies for bacterial surface proteomics. Curr Opin Microbiol 2006, 9, (3), 320-9.

29. Calvo, E.; Pucciarelli, M. G.; Bierne, H.; Cossart, P.; Albar, J. P.; Garcia-Del Portillo, F., Analysis of the Listeria cell wall proteome by two-dimensional nanoliquid chromatography coupled to mass spectrometry. Proteomics 2005, 5, (2), 433-43. 
30. Pucciarelli, M. G.; Calvo, E.; Sabet, C.; Bierne, H.; Cossart, P.; Garcia-del Portillo, F., Identification of substrates of the Listeria monocytogenes sortases A and B by a non-gel proteomic analysis. Proteomics 2005, 5, (18), 4808-17.

31. Severin, A.; Nickbarg, E.; Wooters, J.; Quazi, S. A.; Matsuka, Y. V.; Murphy, E.; Moutsatsos, I. K.; Zagursky, R. J.; Olmsted, S. B., Proteomic analysis and identification of Streptococcus pyogenes surface-associated proteins. J Bacteriol 2007, 189, (5), 1514-22.

32. Bradley, A. J.; Leach, K. A.; Breen, J. E.; Green, L. E.; Green, M. J., Survey of the incidence and aetiology of mastitis on dairy farms in England and Wales. Vet Rec 2007, 160, (8), 253-7.

33. Hillerton, J. E.; Shearn, M. F.; Teverson, R. M.; Langridge, S.; Booth, J. M., Effect of pre-milking teat dipping on clinical mastitis on dairy farms in England. $J$ Dairy Res 1993, 60, (1), 31-41.

34. Ward, P. N.; Holden, M. T.; Leigh, J. A.; Lennard, N.; Bignell, A.; Barron, A.; Clark, L.; Quail, M. A.; Woodward, J.; Barrell, B. G.; Egan, S. A.; Field, T. R.; Maskell, D.; Kehoe, M.; Dowson, C. G.; Chanter, N.; Whatmore, A. M.; Bentley, S. D.; Parkhill, J., Evidence for niche adaptation in the genome of the bovine pathogen Streptococcus uberis. BMC Genomics 2009, 10, 54.

35. Ward, P. N.; Field, T. R.; Ditcham, W. G.; Maguin, E.; Leigh, J. A., Identification and disruption of two discrete loci encoding hyaluronic acid capsule biosynthesis genes hasA, hasB, and hasC in Streptococcus uberis. Infect Immun 2001, 69, (1), 392-9.

36. Taylor, D. L.; Ward, P. N.; Rapier, C. D.; Leigh, J. A.; Bowler, L. D., Identification of a differentially expressed oligopeptide binding protein (OppA2) in Streptococcus uberis by representational difference analysis of cDNA. $J$ Bacteriol 2003, 185, (17), 5210-9.

37. Bierne, H.; Mazmanian, S. K.; Trost, M.; Pucciarelli, M. G.; Liu, G.; Dehoux, P.; Jansch, L.; Garcia-del Portillo, F.; Schneewind, O.; Cossart, P., Inactivation of the srtA gene in Listeria monocytogenes inhibits anchoring of surface proteins and affects virulence. Mol Microbiol 2002, 43, (4), 869-81.

38. Atrazhev, A. M.; Elliott, J. F., Simplified desalting of ligation reactions immediately prior to electroporation into E. coli. Biotechniques 1996, 21, (6), 1024.

39. Taylor, G. K.; Goodlett, D. R., Rules governing protein identification by mass spectrometry. Rapid Commun Mass Spectrom 2005, 19, (23), 3420.

40. Ton-That, H.; Liu, G.; Mazmanian, S. K.; Faull, K. F.; Schneewind, O., Purification and characterization of sortase, the transpeptidase that cleaves surface proteins of Staphylococcus aureus at the LPXTG motif. Proc Natl Acad Sci $U$ S A 1999, 96, (22), 12424-9.

41. Burne, R. A.; Penders, J. E., Characterization of the Streptococcus mutans GS-5 fruA gene encoding exo-beta-D-fructosidase. Infect Immun 1992, 60, (11), 4621-32.

42. Burne, R. A.; Schilling, K.; Bowen, W. H.; Yasbin, R. E., Expression, purification, and characterization of an exo-beta-D-fructosidase of Streptococcus mutans. J Bacteriol 1987, 169, (10), 4507-17. 
43. Wexler, D. L.; Penders, J. E.; Bowen, W. H.; Burne, R. A., Characteristics and cariogenicity of a fructanase-defective Streptococcus mutants strain. Infect Immun 1992, 60, (9), 3673-81.

44. Ferretti, J. J.; Russell, R. R.; Dao, M. L., Sequence analysis of the wallassociated protein precursor of Streptococcus mutans antigen A. Mol Microbiol 1989, 3, (4), 469-78.

45. Barnett, T. C.; Scott, J. R., Differential recognition of surface proteins in Streptococcus pyogenes by two sortase gene homologs. J Bacteriol 2002, 184, (8), 2181-91.

46. Berge, A.; Bjorck, L., Streptococcal cysteine proteinase releases biologically active fragments of streptococcal surface proteins. J Biol Chem 1995, 270, (17), 9862-7.

47. Moshynskyy, I.; Jiang, M.; Fontaine, M. C.; Perez-Casal, J.; Babiuk, L. A.; Potter, A. A., Characterization of a bovine lactoferrin binding protein of Streptococcus uberis. Microb Pathog 2003, 35, (5), 203-15.

48. Harmon, R. J.; Schanbacher, F. L.; Ferguson, L. C.; Smith, K. L., Changes in lactoferrin, immunoglobulin $\mathbf{G}$, bovine serum albumin, and alpha-lactalbumin during acute experimental and natural coliform mastitis in cows. Infect Immun 1976, 13, (2), 533-42.

49. Chaneton, L.; Tirante, L.; Maito, J.; Chaves, J.; Bussmann, L. E., Relationship between milk lactoferrin and etiological agent in the mastitic bovine mammary gland. J Dairy Sci 2008, 91, (5), 1865-73.

50. Rainard, P., Bacteriostatic activity of bovine milk lactoferrin against mastitic bacteria. Vet Microbiol 1986, 11, (4), 387-92.

51. Fischetti, V. A.; Pancholi, V.; Schneewind, O., Conservation of a hexapeptide sequence in the anchor region of surface proteins from gram-positive cocci. $\mathrm{Mol}$ Microbiol 1990, 4, (9), 1603-5.

52. Kruger, R. G.; Otvos, B.; Frankel, B. A.; Bentley, M.; Dostal, P.; McCafferty, D. G., Analysis of the substrate specificity of the Staphylococcus aureus sortase transpeptidase SrtA. Biochemistry 2004, 43, (6), 1541-51.

53. Kleerebezem, M.; Boekhorst, J.; van Kranenburg, R.; Molenaar, D.; Kuipers, O. P.; Leer, R.; Tarchini, R.; Peters, S. A.; Sandbrink, H. M.; Fiers, M. W.; Stiekema, W.; Lankhorst, R. M.; Bron, P. A.; Hoffer, S. M.; Groot, M. N.; Kerkhoven, R.; de Vries, M.; Ursing, B.; de Vos, W. M.; Siezen, R. J., Complete genome sequence of Lactobacillus plantarum WCFS1. Proc Natl Acad Sci $U S A$ 2003, 100, (4), 1990-5.

54. Gardy, J. L.; Laird, M. R.; Chen, F.; Rey, S.; Walsh, C. J.; Ester, M.; Brinkman, F. S., PSORTb v.2.0: expanded prediction of bacterial protein subcellular localization and insights gained from comparative proteome analysis. Bioinformatics 2005, 21, (5), 617-23.

55. Tettelin, H.; Masignani, V.; Cieslewicz, M. J.; Donati, C.; Medini, D.; Ward, N. L.; Angiuoli, S. V.; Crabtree, J.; Jones, A. L.; Durkin, A. S.; Deboy, R. T.; Davidsen, T. M.; Mora, M.; Scarselli, M.; Margarit y Ros, I.; Peterson, J. D.; Hauser, C. R.; Sundaram, J. P.; Nelson, W. C.; Madupu, R.; Brinkac, L. M.; Dodson, R. J.; Rosovitz, M. J.; Sullivan, S. A.; Daugherty, S. C.; Haft, D. H.; Selengut, J.; Gwinn, M. L.; Zhou, L.; Zafar, N.; Khouri, H.; Radune, D.; Dimitrov, 
G.; Watkins, K.; O'Connor, K. J.; Smith, S.; Utterback, T. R.; White, O.; Rubens, C. E.; Grandi, G.; Madoff, L. C.; Kasper, D. L.; Telford, J. L.; Wessels, M. R.; Rappuoli, R.; Fraser, C. M., Genome analysis of multiple pathogenic isolates of Streptococcus agalactiae: implications for the microbial "pan-genome". Proc Natl Acad Sci U S A 2005, 102, (39), 13950-5.

56. Holden, M. T.; Heather, Z.; Paillot, R.; Steward, K. F.; Webb, K.; Ainslie, F.; Jourdan, T.; Bason, N. C.; Holroyd, N. E.; Mungall, K.; Quail, M. A.; Sanders, M.; Simmonds, M.; Willey, D.; Brooks, K.; Aanensen, D. M.; Spratt, B. G.; Jolley, K. A.; Maiden, M. C.; Kehoe, M.; Chanter, N.; Bentley, S. D.; Robinson, C.; Maskell, D. J.; Parkhill, J.; Waller, A. S., Genomic evidence for the evolution of Streptococcus equi: host restriction, increased virulence, and genetic exchange with human pathogens. PLoS Pathog 2009, 5, (3), e1000346.

57. Hoskins, J.; Alborn, W. E., Jr.; Arnold, J.; Blaszczak, L. C.; Burgett, S.; DeHoff, B. S.; Estrem, S. T.; Fritz, L.; Fu, D. J.; Fuller, W.; Geringer, C.; Gilmour, R.; Glass, J. S.; Khoja, H.; Kraft, A. R.; Lagace, R. E.; LeBlanc, D. J.; Lee, L. N.; Lefkowitz, E. J.; Lu, J.; Matsushima, P.; McAhren, S. M.; McHenney, M.; McLeaster, K.; Mundy, C. W.; Nicas, T. I.; Norris, F. H.; O'Gara, M.; Peery, R. B.; Robertson, G. T.; Rockey, P.; Sun, P. M.; Winkler, M. E.; Yang, Y.; Young-Bellido, M.; Zhao, G.; Zook, C. A.; Baltz, R. H.; Jaskunas, S. R.; Rosteck, P. R., Jr.; Skatrud, P. L.; Glass, J. I., Genome of the bacterium Streptococcus pneumoniae strain R6. J Bacteriol 2001, 183, (19), 5709-17.

58. Banks, D. J.; Porcella, S. F.; Barbian, K. D.; Beres, S. B.; Philips, L. E.; Voyich, J. M.; DeLeo, F. R.; Martin, J. M.; Somerville, G. A.; Musser, J. M., Progress toward characterization of the group A Streptococcus metagenome: complete genome sequence of a macrolide-resistant serotype M6 strain. J Infect Dis 2004, 190, (4), 727-38.

59. Smoot, J. C.; Barbian, K. D.; Van Gompel, J. J.; Smoot, L. M.; Chaussee, M. S.; Sylva, G. L.; Sturdevant, D. E.; Ricklefs, S. M.; Porcella, S. F.; Parkins, L. D.; Beres, S. B.; Campbell, D. S.; Smith, T. M.; Zhang, Q.; Kapur, V.; Daly, J. A.; Veasy, L. G.; Musser, J. M., Genome sequence and comparative microarray analysis of serotype M18 group A Streptococcus strains associated with acute rheumatic fever outbreaks. Proc Natl Acad Sci U S A 2002, 99, (7), 4668-73. 
Table on contents synopsis

\section{S. uberis}

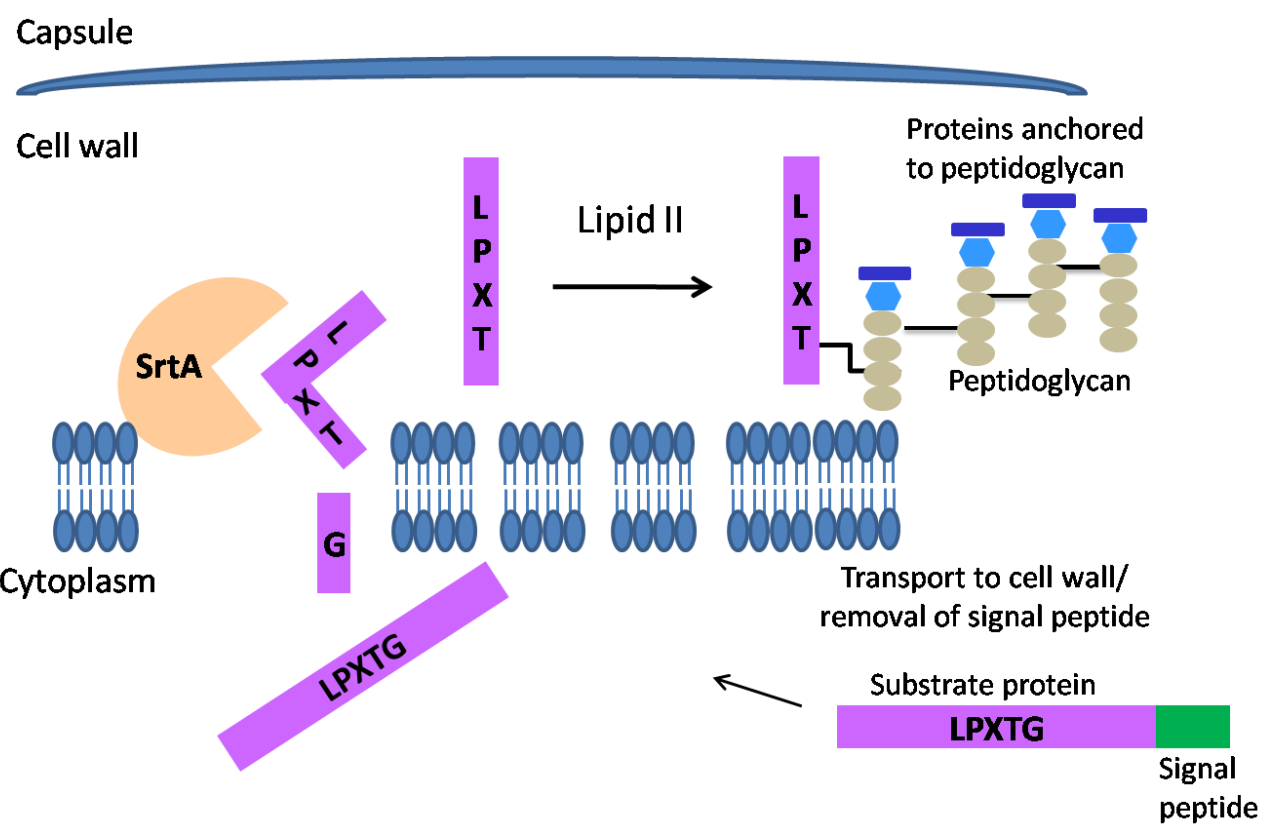

Sortase (SrtA) is responsible for covalently anchoring a subset of proteins to cell walls of Gram positive bacteria, often through a C-terminal motif of LPXTG. In the absence of SrtA, these proteins are either released or retained only loosely on the bacterial surface. Such anchored proteins are frequently characterised as virulence determinants and considered prime targets for therapeutics and vaccine development. Intra-mammary infection with Streptococcus uberis is one of the most common causes of mastitis in UK with major economic and animal welfare implications. Comparison of trypsinised stringent cell wall extracts of $S$. uberis and a srtA mutant by LCMS/MS allowed the identification of nine proteins likely to be anchored by SrtA. Two anchoring motifs are present in this protein subset, the traditional LPXTG and the alternate LPXXXD/E, which highlights the potential for the presence of alternate cell wall anchoring motifs for this and a number of other streptococcal species. 